\title{
Changes in precipitation with climate change
}

\author{
Kevin E. Trenberth* \\ National Center for Atmospheric Research, Box 3000, Boulder, Colorado 80307, USA
}

\begin{abstract}
There is a direct influence of global warming on precipitation. Increased heating leads to greater evaporation and thus surface drying, thereby increasing the intensity and duration of drought. However, the water holding capacity of air increases by about $7 \%$ per $1^{\circ} \mathrm{C}$ warming, which leads to increased water vapor in the atmosphere. Hence, storms, whether individual thunderstorms, extratropical rain or snow storms, or tropical cyclones, supplied with increased moisture, produce more intense precipitation events. Such events are observed to be widely occurring, even where total precipitation is decreasing: 'it never rains but it pours!' This increases the risk of flooding. The atmospheric and surface energy budget plays a critical role in the hydrological cycle, and also in the slower rate of change that occurs in total precipitation than total column water vapor. With modest changes in winds, patterns of precipitation do not change much, but result in dry areas becoming drier (generally throughout the subtropics) and wet areas becoming wetter, especially in the mid- to high latitudes: the 'rich get richer and the poor get poorer'. This pattern is simulated by climate models and is projected to continue into the future. Because, with warming, more precipitation occurs as rain instead of snow and snow melts earlier, there is increased runoff and risk of flooding in early spring, but increased risk of drought in summer, especially over continental areas. However, with more precipitation per unit of upward motion in the atmosphere, i.e. 'more bang for the buck', atmospheric circulation weakens, causing monsoons to falter. In the tropics and subtropics, precipitation patterns are dominated by shifts as sea surface temperatures change, with El Niño a good example. The volcanic eruption of Mount Pinatubo in 1991 led to an unprecedented drop in land precipitation and runoff, and to widespread drought, as precipitation shifted from land to oceans and evaporation faltered, providing lessons for possible geoengineering. Most models simulate precipitation that occurs prematurely and too often, and with insufficient intensity, resulting in recycling that is too large and a lifetime of moisture in the atmosphere that is too short, which affects runoff and soil moisture.
\end{abstract}

KEY WORDS: Climate change $\cdot$ Precipitation $\cdot$ Storms $\cdot$ Drought $\cdot$ Extremes $\cdot$ Floods $\cdot$ Geoengineering $\cdot$ Climate models

Resale or republication not permitted without written consent of the publisher

\section{INTRODUCTION}

Heated by the sun's radiation, the ocean and land surface evaporate water, which then moves around with winds in the atmosphere, condenses to form clouds, and falls back to the Earth's surface as rain or snow, with the flow to oceans via rivers completing the global hydrological (water) cycle.

Precipitation varies from year to year and over decades, and changes in amount, intensity, frequency, and type (e.g. snow vs. rain) affect the environment and society. Steady moderate rains soak into the soil and benefit plants, while the same amounts of rainfall in a short period of time may cause local flooding and runoff, leaving soils much drier at the end of the day (Fig. 1). Snow may remain on the ground for some months before it melts and runs off. Even with identical amounts, the climate can be very different if the frequency and intensity of precipitation differ, as illustrated in Fig. 1, and in general the climate is changing from being more like that at Station (Stn) B in Fig. 1 to that at Stn A. These examples highlight the fact to the characteristics of precipitation are just as vital as the amount, in terms of the effects on the soil moisture and stream flow.

Hydrological extreme events are typically defined as floods and droughts. Floods are associated with ex- 


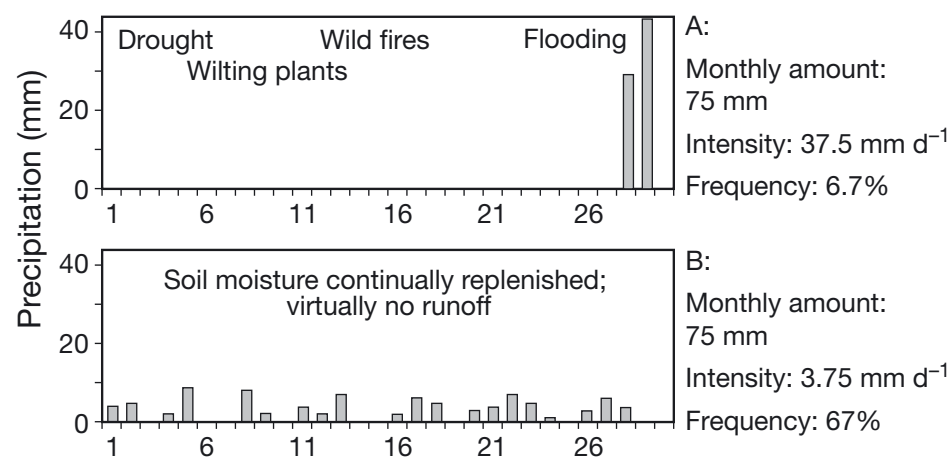

Fig. 1. Hypothetical daily amounts of precipitation for a month at Stations A and B, including the monthly amounts, average intensity per day conditional on rain occurring, and frequency. Consequences for runoff and plants are noted in each panel

tremes in rainfall (from tropical storms, thunderstorms, orographic rainfall, widespread extratropical cyclones, etc.), while droughts are associated with a lack of precipitation and often extremely high temperatures that contribute to drying. Floods are often fairly local and develop on short time scales, while droughts are extensive and develop over months or years. Both can be mitigated; floods by good drainage systems and drought by irrigation, for instance. Nonetheless, daily newspaper headlines of floods and droughts reflect the critical importance of the water cycle, in particular precipitation, in human affairs. World flood damage estimates are in the billions of U.S. dollars annually, with 1000s of lives lost; while drought costs are of similar magnitude and often lead to devastating wildfires and heat waves. The loss of life and property from extreme hydrological events has therefore caused society to focus on the causes and predictability of these events. Tropical cyclones typically have the highest property damage loss of any extreme event, and are therefore of great interest to state and local disaster preparedness organizations, as well as to the insurance industry (Murnane 2004).

Evidence is building that human-induced climate change (global warming), is changing precipitation and the hydrological cycle, and especially the extremes. This article first discusses the observed changes (Section 2) and then considers the processes involved and the conceptual basis for understanding changes in precipitation, floods, and drought, and future prospects (Sections 3 and 4). Climate models (Section 5) have been used as a guide to future changes, but are challenged in their ability to correctly simulate patterns, seasonal variations, and characteristics of precipitation, and hence their results must be used with caution (e.g. Kharin et al. 2007, Liepert \& Previdi 2009). Outstanding issues are briefly discussed in Section 6.

\section{OBSERVED CHANGES IN PRECIPITATION}

\subsection{Mean fields}

There is a very strong relationship between total column water vapor (TCWV, also known as precipitable water) and sea-surface temperatures (SSTs) over the oceans (Trenberth et al. 2005) in both the overall patterns and their variations over time (e.g. Fig. 2 for January and July). The Clausius-Clapeyron (C-C) equation describes the water-holding capacity of the atmosphere as a function of temperature, and typical values are about $7 \%$ change for $1^{\circ} \mathrm{C}$ change in temperature. For SST changes, the TCWV varies with slightly larger values owing to the increase in atmospheric temperature perturbations with height, especially in the tropics. Accordingly, the largest average TCWV values occur over the tropical Pacific Warm Pool, where highest large-scale values of SSTs typically reside. The annual mean and January and July values are given in Table 1 for the global, ocean, and land domains. Global surface air temperatures are higher in Northern Hemisphere summers, and this is reflected in much higher TCWV values over land.

The observed TCWV and precipitation mean annual cycles also show very strong relationships in the tropics and subtropics, but not in the extratropics (Fig. 2). Atmospheric convergence at low levels tends to occur in close association with the highest SSTs, although the factors extend beyond the SST values alone to include the gradients in SSTs, which are reflected in surface pressure gradients and thus in the winds. Accordingly, in the tropics, the precipitation patterns tend to mimic the patterns of TCWV and thus SSTs, but with much more structure and sharper edges, as overturning circulations, such as those associated with the Hadley Cell and monsoons, develop and create strong areas of subsidence that dry out the troposphere above the boundary layer.

The mean TCWV falls off at higher latitudes in both hemispheres, along with the SSTs, but precipitation has a secondary maximum over the oceans associated with mid-latitude storm tracks. In January these are strongly evident over the North Pacific and Atlantic Oceans and, to a lesser extent, throughout the southern oceans. The southern ocean storm tracks are strongest in the transition seasons and broadest in the southern winter, while the northern ocean storm tracks become weaker in the northern summer. The absence of relationships between mean TCWV and precipitation in the extratropics highlights the very transient nature of precipitation events that are associated with extratropical cyclones, while in the tropics there is a much stronger mean-flow component associated with monsoons and the Hadley circulation. 

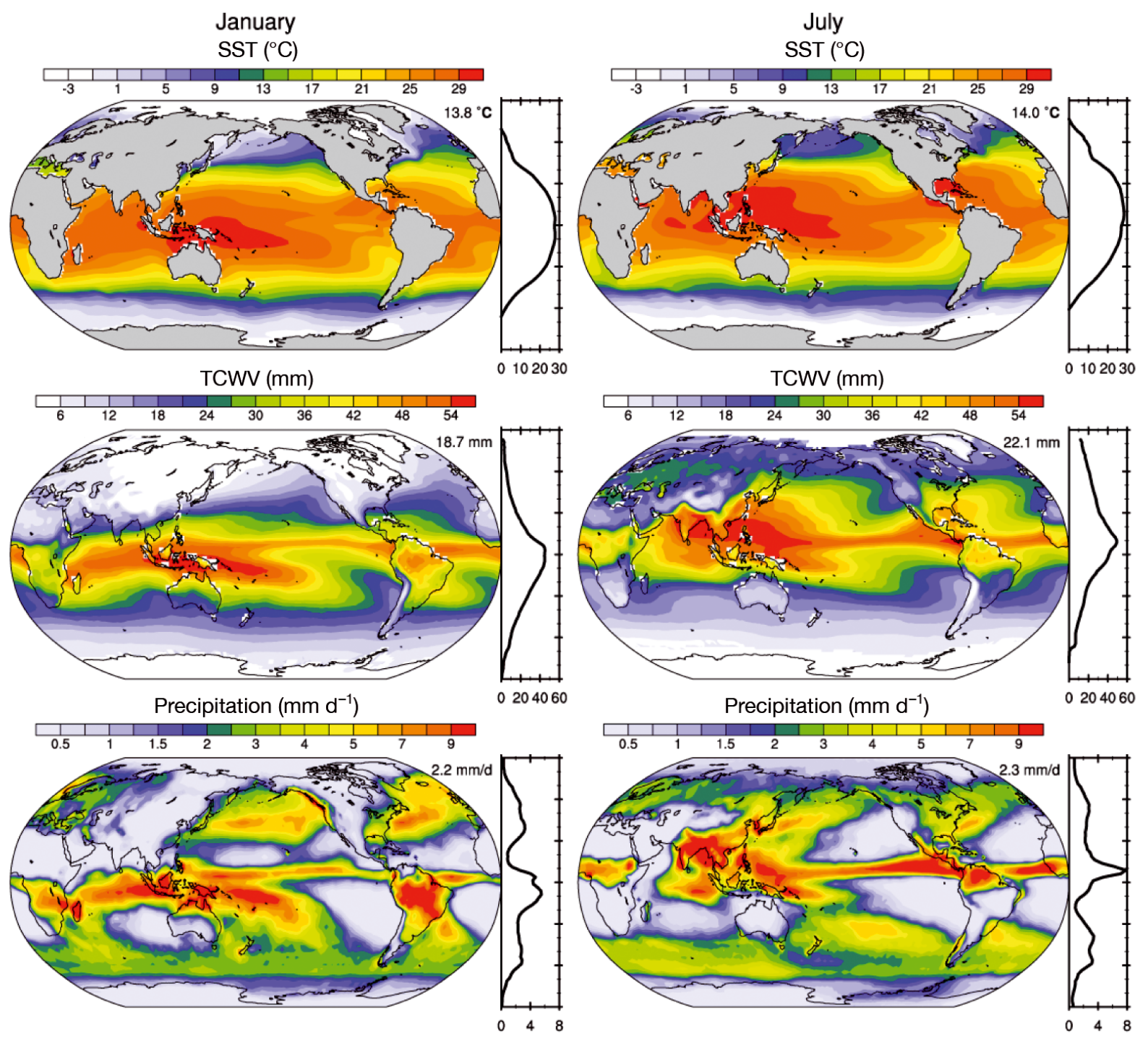

Fig. 2. Mean sea-surface temperature (SST), total column water vapour (TCWV), and precipitation for January (left panels) and July (right panels). SSTs are from Smith et al. (2008) for 1979-2008; TCWV is from SSM/I over ocean and National Centers for Environmental Prediction reanalyses over land (see Trenberth et al. 2007b) for 1987-2008; and precipitation is from the Global Precipitation Climatology Project Ver. 2.1 for 1979-2008 based on Huffman et al. (2009). Graphs to the right: zonal means; values, top right: global mean

Difficulties in the measurement of precipitation remain an area of concern in quantifying the extent to which global and regional scale precipitation has changed. In situ measurements are especially impacted by wind effects on the gauge catch, especially for snow and light rain (Adam \& Lettenmaier 2003), and few measurements exist in areas of steep and complex topography (Adam et al. 2006). For remotely sensed measurements (radar and space-based), the greatest problems are that only measurements of instantaneous rates can be made and there are uncertainties in algorithms for converting radiometric measurements (radar, microwave, infrared) into precipitation rates at the surface (e.g. Krajewski et al. 2010). To gain confidence in observations, it is useful to examine the consistency of changes in a variety of complementary moisture variables, including both remotely sensed and gauge-measured precipitation, drought, evaporation, atmospheric moisture, soil moisture, and stream flow, although uncertainties exist with all of these variables as well (Huntington 2006).

\subsection{Changes in water vapor}

As the climate warms, water-holding capacity increases with higher temperatures according to the C-C relationship, and, hence, it is natural to expect increases in water vapor amounts because relative humidity is more likely to remain about the same. Changes 
Table 1. Global, ocean, and land means for annual, January, and July seasurface temperature (SST), total column water vapor (TCWV), and precipitation

\begin{tabular}{|lccccccccc|}
\hline & \multicolumn{2}{c}{$\mathrm{SST}\left({ }^{\circ} \mathrm{C}\right)$} & \multicolumn{3}{c}{$\mathrm{TCWV}(\mathrm{mm})$} & \multicolumn{5}{c|}{ Precipitation $\left(\mathrm{mm} \mathrm{d}^{-1}\right)$} \\
& Annual & Jan & Jul & Annual & Jan & Jul & Annual & Jan & Jul \\
\hline Global ocean & \multirow{2}{*}{18.2} & \multirow{2}{*}{18.2} & 18.3 & & & & & & \\
Global & & & & 24.2 & 23.1 & 25.8 & 2.67 & 2.69 & 2.70 \\
Ocean & & & 26.6 & 26.3 & 27.0 & 2.87 & 2.92 & 2.79 \\
Land & & & 18.5 & 15.5 & 23.0 & 2.21 & 2.16 & 2.50 \\
\hline
\end{tabular}

satellites. Gu et al. (2007) documented global and tropical rainfall changes using the Global Precipitation Climatology Project (GPCP), and found near zero global changes, but with large variability and changes over land that are largely compensated for by opposite changes over the oceans. This is especially the case for El Niño events (Trenberth \& Dai 2007). The global

in TCWV and humidity are evident in observations. At the surface, there are clear indications of increases in specific humidity (Dai 2006a, Willett et al. 2008). Over oceans, the increases are consistent with C-C expectations, with a constant relative humidity, while increases are somewhat lower over land, especially where water availability is limited. In the troposphere the largest fluctuations in TCWV occur with El NiñoSouthern Oscillation (ENSO) events (Trenberth et al. 2005), although a sharp drop was evident following the Mount Pinatubo eruption (Durre et al. 2009). TCWV has also increased at rates consistent with C-C for the period 1987-2004 (1.3\% decade ${ }^{-1}$ ) (Trenberth et al. 2005, 2007a), and the relationship with changes in SSTs is sufficiently strong that it is possible to deduce an increase of about $4 \%$ in TCWV over the oceans since the 1970s. Over land in the Northern Hemisphere, Durre et al. (2009) found trends indicating an increase of $0.45 \mathrm{~mm}$ decade $^{-1}(1973-2006)$ in TCWV, but homogeneity issues remain in the radiosonde records. Water vapor in the upper troposphere has also increased at a rate consistent with a fairly constant relative humidity (Soden et al. 2005). Santer et al. (2007) have identified a strong human influence in the recent water vapor increases.

The observed increases in water vapor affect both the greenhouse effect, thus providing a positive feedback to climate change, and the hydrological cycle, by providing more atmospheric moisture for all storms to feed upon. Accordingly, it has ramifications for precipitation.

\subsection{Changes in precipitation}

A comprehensive summary of observed changes in precipitation is given in the Intergovernmental Panel on Climate Change (IPCC) Fourth Assessment (AR4) (Trenberth et al. 2007a), and the reader is referred there for the extensive bibliography. Schlosser \& Houser (2007) and Wentz et al. (2007) provided recent estimates of precipitation and their trends. However, the precipitation and evaporation estimates of Schlosser $\&$ Houser (2007) are out of balance and reveal likely spurious changes over time associated with changes in mean GPCP precipitation is $2.67 \mathrm{~mm} \mathrm{~d}^{-1}$, corresponding to $76 \mathrm{~W} \mathrm{~m}^{-2}$ in terms of latent heating. An update of the $\mathrm{Gu}$ et al. analysis (also Huffman et al. 2009) confirms that there have been no significant trends since 1979 (Fig. 3). This is in marked contrast to the results of Wentz et al. (2007), who found a significant upward trend from 1987 to 2006, but their results depend critically on the time period and also the dataset used. Fig. 3 also reveals an upward trend over the period observed by Wentz, but it is not robust as it does not stand up to addition of data at either end.

New observations suggest that the GPCP values may be an underestimate, because they may not adequately capture low-level warm rain in the extratropics, and the high extremes could be underestimated as well. Trenberth et al. $(2007 b, 2009)$ assessed the evidence and increased the GPCP estimate by $5 \%$ over the ocean to better satisfy energy budget constraints, so that the latent heat released by precipitation was assigned a value of $80 \mathrm{~W} \mathrm{~m}^{-2}$. The main variations in the global mean precipitation occur in the tropics (Fig. 3), where TCWV is largest, in association with ENSO events. However, even though the regional variations of precipitation with ENSO are huge (cf. Trenberth \& Caron 2000), the zonal and global means are much more muted, owing to cancellation between dipole structures, although ENSO accounts for the main land-sea variations (Gu et al. 2007).

Over land, the precipitation record extends throughout the 20th century, and large variations occur from year to year and on decadal time scales. Nonetheless, some large-scale patterns of systematic change are evident (Trenberth et al. 2007a). In general, there have been decreases in precipitation in the subtropics and tropics outside of the monsoon trough, and increases in land precipitation at higher latitudes, notably over North America, Eurasia, and Argentina. The decreases are especially evident in the Mediterranean, southern Asia, and throughout Africa. In the more northern regions, more precipitation falls as rain rather than snow (e.g. Mote 2003, Knowles et al. 2006). The liquidprecipitation season has become longer by up to $3 \mathrm{wk}$ in some regions of the boreal high latitudes over the last 50 yr (Trenberth et al. 2007a), owing, in particular, to an earlier onset of spring. Similar changes can be 


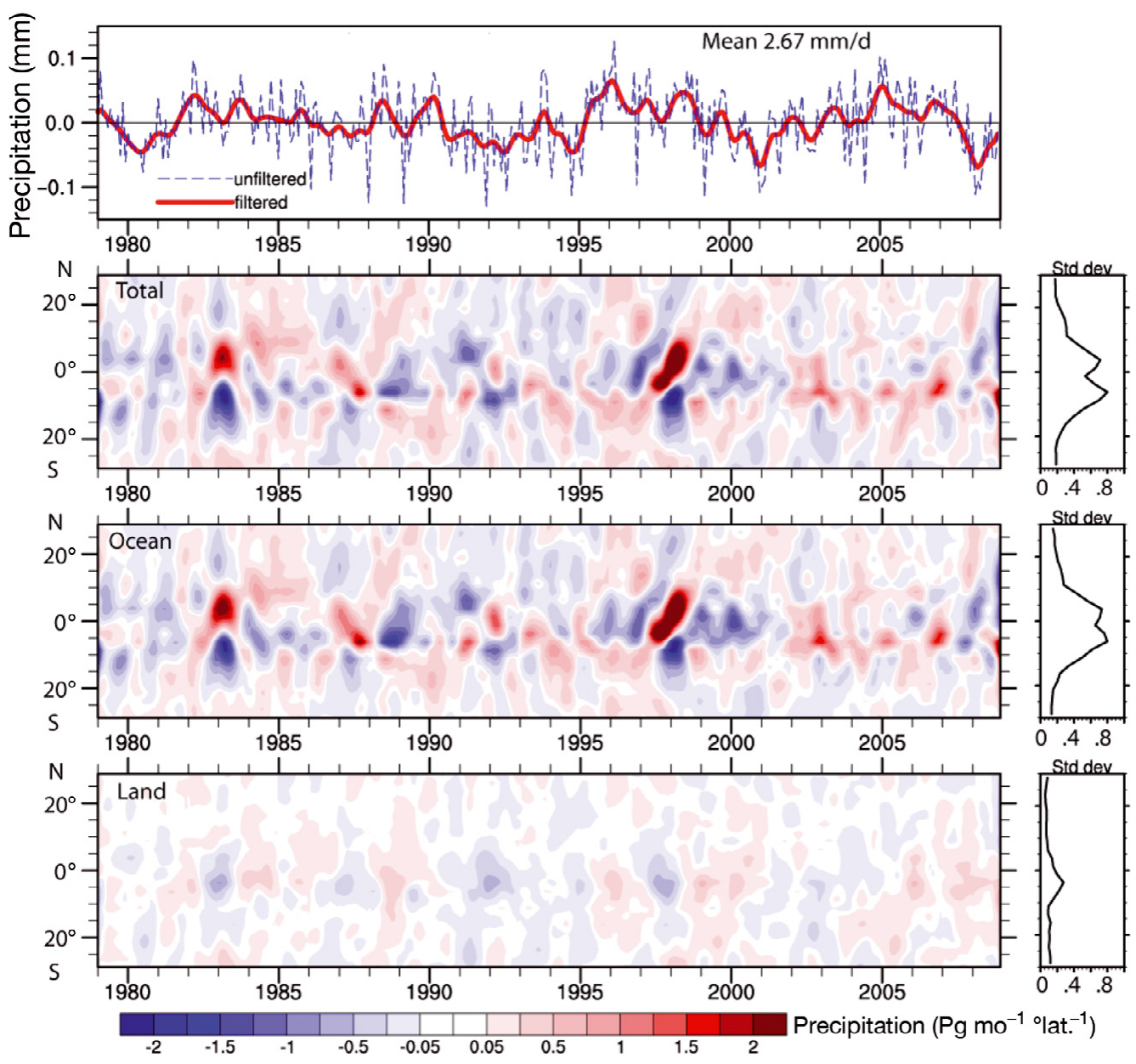

Fig. 3. Time series of precipitation from the Global Precipitation Climatology Project relative to their 1979-2008 mean of 2.67 mm $\mathrm{d}^{-1}$ globally (top panel). Global values are dominated by variations in the tropics. Zonally integrated values are given in the other 3 panels for $30^{\circ} \mathrm{N}-30^{\circ} \mathrm{S}$ for total, ocean, and land precipitation (panels labeled accordingly). Standard deviations are given at right. Land values are typically a factor of 5 lower than those for ocean. The dominant variations are associated with El Niño-Southern Oscillation, but large cancellation occurs both in longitude and latitude. The values are smoothed with a 13-term filter to remove fluctuations of less than about a year

inferred over the oceans from the large-scale patterns of change in salinity from the 1950s-1960s versus the 1990s-2000s (IPCC 2007). Higher salinities of the oceans at low latitudes and freshening at high latitudes of both hemispheres are evident.

Another perspective on total land precipitation comes from examining precipitation in conjunction with river discharge into the oceans (Dai et al. 2009) for the period 1948-2005 (see Fig. 4). This reinforces the other analyses mentioned above. The results alter conclusions published earlier (Gedney et al. 2006), as there is large sensitivity to how missing data are treated. At interannual to decadal time scales, results revealed large variations in continental discharge correlated with ENSO for the discharge into the Pacific, Atlantic, Indian, and global oceans as a whole (but not with discharges into the Arctic Ocean and the Mediter- ranean and Black Seas). For most ocean basins and the global oceans as a whole, the discharge data show downward trends, and precipitation changes are found to be the main cause. For the Arctic drainage areas, upward trends in streamflow from 1948 to 2005 were apparently not accompanied by increasing precipitation (although the data may not be adequate), especially over the Siberia, and decreasing trends in snow cover and soil ice water content over the northern high-latitudes may have contributed to the runoff increases in these regions.

The global land values of precipitation after 1950 (Fig. 5) (Trenberth \& Dai 2007) show a slight decrease overall for this time period, but with a singular drop in 1992 in both streamflow and precipitation that is well outside the realm of all other variations and is associated with the Mount Pinatubo eruption in 1991 (Tren- 


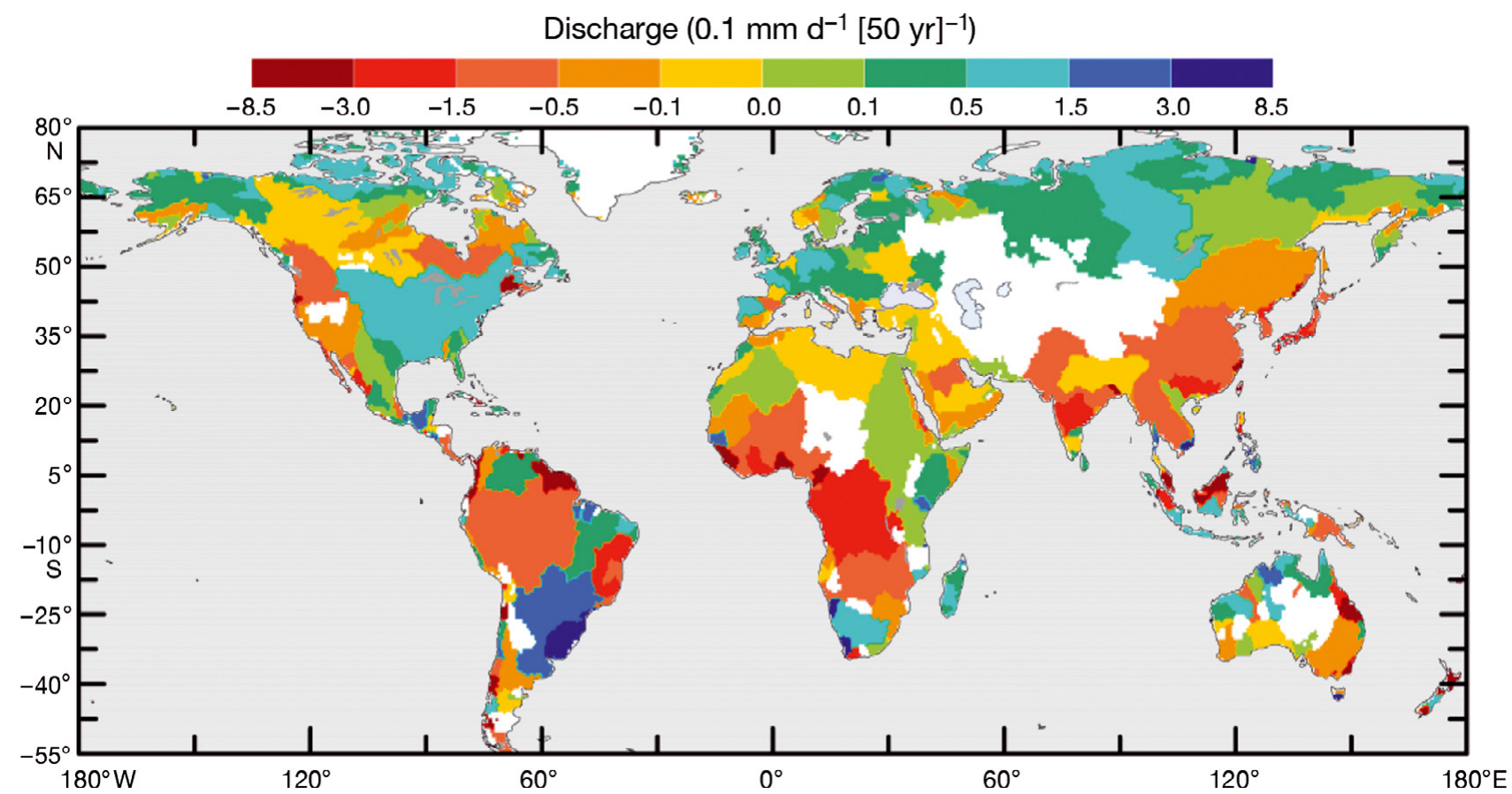

Fig. 4. Linear trends in river discharge as linked to the associated drainage basin (adapted from Dai et al. 2009)

berth \& Dai 2007). The abrupt drop in incoming net radiation from the sun led to a brief cooling of the land and then the ocean, which initially caused a shift in precipitation away from the land and then decreased the global evaporation, TCWV (Durre et al. 2009), and global precipitation.

Drought has also generally increased throughout the 20th century (Dai et al. 2004, Trenberth et al. 2007a), as measured by the Palmer drought severity index (PDSI). Dai et al. (2004) show that very dry land areas across the globe (defined as areas with PDSI less than -3.0) have more than doubled in extent since the 1970s. Drought is generally more widespread during El Niño events, and became very widespread for a year or so after the Mount Pinatubo eruption. Increases in drought are associated with the redistribution of precipitation and with more rainfall over the ocean than over land during the Pacific Decadal Oscillation, but also with increases in surface temperature and the associated increased atmospheric demand for moisture, which increases evapotranspiration.

The character of precipitation is also changing. In particular, increases in heavy rains are generally found to be occurring in most places, even when mean precipitation is not increasing (Easterling et al. 2000, Peterson et al.
2002, Klein Tank \& Können 2003, Groisman et al. 2004, 2005, Alexander et al. 2006, Klein Tank et al. 2006, Trenberth et al. 2007a, Groisman \& Knight 2008). Much of this increase occurred during the last 3 decades of the century. Although flooding has increased in some areas, and in association with tropical cyclones and hurricanes, land-use change alters risk, and flood mitigation projects are pervasive in reducing flood risks. Nevertheless, extreme flooding has increased in the 20th century (Milly et al. 2002). Karl \& Trenberth (2003) and Allan \& Soden (2008) find a distinct link between higher rainfall extremes and temperatures.

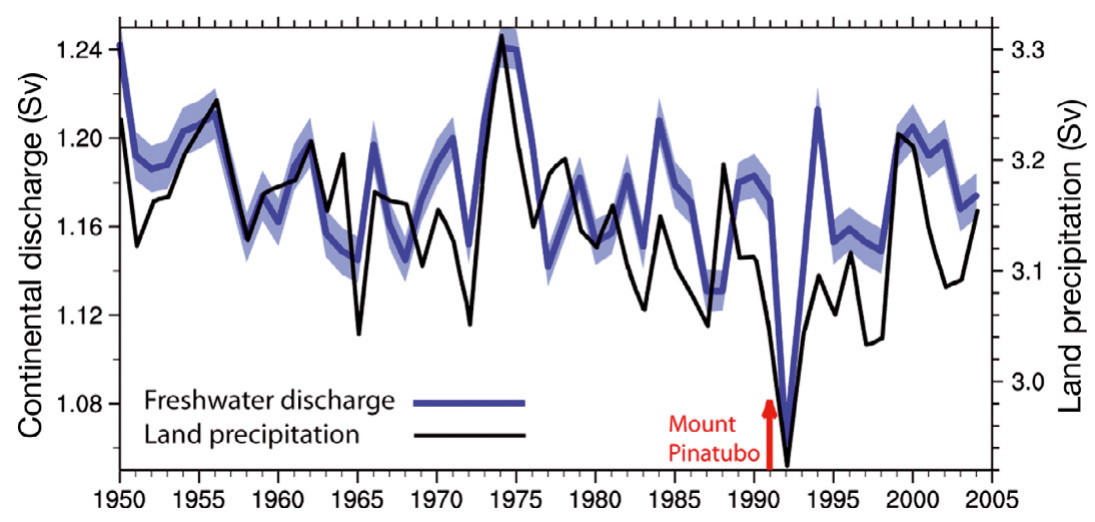

Fig. 5. Time series of global river discharge into the oceans and associated land precipitation (adapted from Trenberth \& Dai 2007). Arrow: timing of Mount Pinatubo eruption 


\subsection{Patterns of change}

Local and regional changes in the character of precipitation depend a great deal on variability patterns of atmospheric circulation. Some of these observed circulation changes are associated with climate change. A shift in the storm track makes some regions wetter and some-often nearby-drier, leading to complex patterns of change. Large-scale patterns of change in precipitation associated with ENSO dominate the global patterns of variations (Trenberth \& Caron 2000). The distribution and timing of floods and droughts is most profoundly affected by the cycle of El Niño events, particularly in the tropics and over much of the mid-latitudes of Pacific-rim countries (Diaz \& Markgraf 2000). For instance, opposite phases of the ENSO were shown by Trenberth \& Guillemot (1996) to play a role in the 1988 drought and 1993 flood in North America. They showed that both of these events developed as a result of a change in the large-scale atmospheric circulation over the Pacific and across North America, which, in turn, altered the storm tracks into North America.

In recent years precipitation changes have developed a distinctive pattern, whereby the higher latitudes have become wetter and the subtropics and much of the tropics have become drier (Trenberth et al. 2007a). The exception is the monsoon trough in the tropics that denotes the wet season. This distinctive pattern of change is associated with some alterations in atmospheric circulation (Trenberth et al. 2007a), in particular, with increases in the westerly winds at midlatitudes that are associated with 'preferred' patterns of behavior, sometimes called 'modes'. In the Northern Hemisphere, the Northern Annular Mode (NAM) is characteristic, and in the Southern Hemisphere, the Southern Annular Mode (SAM). The NAM is closely related to another phenomenon called the North Atlantic Oscillation (NAO), which is a more regional measure of westerly wind strength over the North Atlantic, mainly in winter. In the European sector, a more positive NAO in the 1990s led to wetter conditions in northern Europe and drier conditions over the Mediterranean and northern African regions (Hurrell et al. 2003).

The prolonged drought in the Sahel-which was very pronounced from the late-1960s to the late1980s - continues, although it is not quite as intense as it was; this drought has been linked, through changes in atmospheric circulation, to changes in tropical SST patterns in the Pacific, Indian, and Atlantic basins (Giannini et al. 2003, Hoerling et al. 2006). Overgrazing and changes in land-use are additional factors of importance. Drought has become widespread throughout much of Africa and more common in the tropics and subtropics.

\section{PRECIPITATION PROCESSES}

Precipitation is the general term for rainfall, snowfall, and other forms of frozen or liquid water falling from clouds. Precipitation is intermittent, and the character of the precipitation when it occurs depends greatly on temperature and the weather situation. The latter determines the storms and supply of moisture through winds and surface evaporation, and how it is gathered together to form clouds. Precipitation forms as water vapor is condensed, usually in rising air that expands and hence cools. The upward motion comes from air rising over mountains, warm air riding over cooler air (warm front), colder air pushing under warmer air (cold front), convection from local heating of the surface, and other weather and cloud systems. Precipitation is therefore also generally dependent on the presence of storms of one sort or another.

As air warms above the freezing point, precipitation turns to rain. In winter, as temperatures drop below freezing point, the air becomes 'freeze dried' and at very low temperatures, below $-10^{\circ} \mathrm{C}$, snow tends to become very light with small flakes or even 'diamond dust'-like. It is only when temperatures are near freezing that huge amounts of snow fall, flakes can be large, and snow can bind together so that one can make snow-men (or snow-women). The same process is essential for creating precipitation. As air rises into regions of lower pressure, it expands and cools, and that cooling causes water vapor to condense and precipitation to form. Consequently, changes in temperature through the $\mathrm{C}-\mathrm{C}$ relationship provide a very fundamental constraint on the amount and type of precipitation through the water vapor content of the air.

On average, the frequency of precipitation over the global oceans is $10.9 \%$ (Stephens \& Ellis 2008), varying in values 2 - to 3 -fold higher at high latitudes than in subtropical regions. Over land, the average values are less and can be almost zero in deserts (see Dai 2001). Because evaporation is a continuous process, the intermittency of precipitation means that typical rates of precipitation conditional upon when it falls are 10- to 25-fold larger than for evaporation. For moderate or heavy falls, precipitation cannot come from TCWV or from evaporation, but has to come from moisture convergence by the storm-scale circulation (Trenberth et al. 2003). Accordingly, storms reach out to gather water vapor over regions that are 10-25 times as large as the precipitation area, or in linear dimensions, have a radius of about 3-5 times the radius of the precipitation domain (Trenberth 1998, 1999a, Trenberth et al. 2003). This rule of thumb appears to work quite well for storms ranging from thunderstorms, to extratropical cyclones, to tropical storms (e.g. Trenberth et al. 2007c). 


\section{UNDERSTANDING PRECIPITATION CHANGES AND THE RELEVANT PROCESSES}

\subsection{Processes involved in changes}

The conceptual basis for changes in precipitation has been outlined by Trenberth (1998, 1999a), Allen \& Ingram (2002), Trenberth et al. (2003), Chou \& Neelin (2004), Neelin et al. (2006), Held \& Soden (2006), and Stephens \& Ellis (2008). Issues relate to changes in the location, type, amount, frequency, intensity, and duration of precipitation, and especially to changes in extremes. As climate varies or changes, several direct influences alter the amount of precipitation, and its intensity, frequency, and type.

The most predictable component of climate change in the future is that associated with human activities (IPCC 2007). Through the burning of fossil fuels, humans are inducing major changes in the composition of the atmosphere by adding carbon dioxide and visible particulates, called aerosols. Other activities add methane and nitrous oxide, which, along with carbon dioxide, are the so-called greenhouse gases (GHGs) that trap outgoing infrared radiation and warm the planet (IPCC 2007). The effect is about $1 \%$ of the natural flow of energy through the climate system (Karl \& Trenberth 2003). Changes in radiative forcing associated with increasing GHGs in the atmosphere produce increased heating at the surface. The actual amount of heating depends critically on various feedbacks, including the water-vapor feedback, the icealbedo feedback, and the effects of changes in clouds (Karl \& Trenberth 2003). One consequence of increased heating from the human-induced greenhouse effect is an increase in temperature. However, another consequence is increased evaporation of surface moisture (Yu \& Weller 2007), thereby changing the hydrological cycle, provided that adequate surface moisture is available (as it always is over the oceans and other wet surfaces).

The following is a summary listing of the important processes involved in the changes that are underway; the individual points are then discussed further:

- The $C$-C effect is important over oceans (abundant moisture) and over land at mid- to high latitudes in winter (Trenberth \& Shea 2005).

- The disparity between increased moisture from C-C and a much smaller change in the amount of total precipitation ensures that there will be a shift in the nature of precipitation events to more intense and less frequent rains: the 'it never rains but it pours' syndrome (Trenberth 1998, Trenberth et al. 2003).

- In the absence of changes in winds, increases in evaporation and moisture mean that more moisture is transported from divergence regions (subtropics) to convergence zones in the tropics and into the storm tracks at higher latitudes, so that wet areas get wetter and dry areas get drier, giving rise to the 'rich get richer and the poor get poorer' syndrome (Chou \& Neelin 2004, Held \& Soden 2006, Neelin et al. 2006, Chou et al. 2009).

- But there are increases in moist static energy and gross moist instability, which enables stronger convection and more intense rains. The upward branch of the Hadley circulation becomes narrower and deeper (Richter \& Xie 2008).

- These also alter the static stability that result in an 'upped ante' for precipitation to occur, resulting in decreases on edges of convergence zones, as it takes more instability to trigger convection (Chou \& Neelin 2004).

- Hence, there are changes in winds that modify the rich get richer syndrome, and convergence zones become narrower. The tropics as a whole become wider, and storm tracks shift polewards (Yin 2005, IPCC 2007).

- The changes in winds change SSTs, and, in the tropics, this has profound effects on where convergence of moisture is favored; hence, the Inter-Tropical Convergence Zone and South Pacific Convergence Zone move, as seen in ENSO events (Trenberth \& Caron 2000), and dipole structures often occur in precipitation anomalies.

- Because moisture transports move latent energy around as a key part of energy transports, with increased moisture, the winds can be less strong and still achieve the same transport that is required to balance the energy budget. Hence, the divergent circulation is apt to be weakened, giving rise to the 'more bang for the buck' syndrome (Vecchi et al. 2006, Held \& Soden 2006).

- There is also a change from snow to rain, especially at the beginning and end of the cold season. Snowpack melts faster and, thus, is diminished at the end of spring (e.g. Mote 2003), leading to less soil moisture in summer and a greater risk of drought, heat waves, and wild fires.

\subsection{Energy constraints}

A key to understanding changes in the hydrological cycle is the energy cycle. Evaporation requires energy, which comes from the sun or downward long-wave radiation. Subsequent precipitation releases latent heat that can affect atmospheric stability and has to be dispersed somehow. The increase in surface evaporation depends on the energy available, as discussed below, and the rate is much less than the $7 \%$ per degree Celsius increase in water vapor from $\mathrm{C}-\mathrm{C}$, although Wentz 
et al. (2007) suggest that this may be underestimated in models. A consequence is that the nature of precipitation must change (Trenberth et al. 2003).

The top-of-atmosphere (TOA) and surface net radiation are affected by changes in albedo, which arise from ice-albedo feedbacks mostly at high latitudes, changes in cloud, and changes in aerosols and indirect effects on clouds. At high latitudes, changes in cloud often compensate for ice-albedo effects, but more generally represent a positive feedback in models (Trenberth \& Fasullo 2009). These processes affect the solar radiation at the surface and, thus, the energy available for sensible and latent heat fluxes. The latter, in turn, are linked to precipitation changes.

Expectations for changes in overall precipitation amounts are complicated by the presence of aerosols (Stevens \& Feingold 2009). Because particulate aerosols block the sun, surface heating is reduced. Absorption of radiation by some, notably carbonaceous, aerosols directly heats the aerosol layer. Otherwise the layer may have been heated by latent heat release following surface evaporation. Hence, these aerosols reduce the hydrological cycle. As aerosol influences tend to be regional, the net expected effect on precipitation over land is especially unclear. In areas where aerosol pollution masks the ground from direct sunlight, decreases in evaporation reduce the overall moisture supply to the atmosphere. The largest decrease recorded in global land precipitation happened in the year after the Mount Pinatubo volcanic eruption, owing to cooling from the aerosol deposited in the stratosphere (Trenberth \& Dai 2007).

However, under increased GHGs, the solar TOA radiation does not change much; thus, the outgoing longwave radiation has to equilibrate to produce the same value, which it does through radiation coming from higher and colder regions of the atmosphere as the planet warms. But increased GHGs produce a great enhancement in downwelling radiation, which is responsible for the increase in surface temperatures; thus, there is some compensation from a larger Plank function response. Nonetheless, a substantial increase remains in the net downwelling long-wave radiation at the surface, which feeds into increases in sensible and latent heat fluxes. It is this process that provides the dominant control over the increase in global precipitation of $2 \%$ per $1 \mathrm{~K}$ increase in temperature (Stephens \& Ellis 2008).

Warming accelerates land-surface drying as heat goes into evaporation of moisture, and this increases the potential incidence and severity of droughts, which has been observed in many places worldwide (Dai et al. 2004). The moisture in the atmosphere then gets carried around by atmospheric winds to where storms are favored. Because weather systems reach out to gather in moisture over extensive regions (see Section 3), ob- served increased amounts of water vapor lead to increased convergence of moisture and, thus, to more intense precipitation and increased risk of heavy rain and snow events (Trenberth 1998, 1999a, Trenberth et al. 2003). In fact, as noted by Trenberth et al. (2003), the rate of increase in precipitation intensity can even exceed the rate of increase of moisture, because the additional latent heat released invigorates the parent storm and further enhances convergence of moisture; many examples of this phenomenon exist (e.g. Liu et al. 2009). However, as the total precipitation amount increases at a much lower rate, the frequency or duration must decrease. Basic theory, climate model simulations, and empirical evidence all confirm that warmer climates, owing to increased water vapor, lead to more intense precipitation events, even when the total annual precipitation is reduced slightly, and with prospects for even stronger events when the overall precipitation amounts increase (Trenberth et al. 2003, Allan \& Soden 2008). Hence, even as the potential for heavier precipitation occurs from increased water vapor amounts, the duration and frequency of events may be curtailed, as it takes longer to recharge the atmosphere with water vapor. A warmer climate, therefore, increases risks of both drought - where it is not raining - and floodswhere it is - but at different times and/or places.

For instance, the summer of 2002 in Europe brought widespread floods, but was followed a year later in 2003 by record breaking heat waves and drought. In the Mediterranean (Alpert et al. 2002) drought is often accompanied by stronger rainfall events. In the summer of 2007 from May to July, widespread flooding in central England (wettest since records began in 1766) was accompanied by drought and record-breaking heat waves (temperatures exceeding $40^{\circ} \mathrm{C}$ ) in southeast Europe (see www.wmo.ch/pages/mediacentre/ press_releases/pr_791_en.html).

In addition, as heat is transported upwards during precipitation, more moisture leads to greater latent heat released, and thus a reduced need for the overall circulation to be as vigorous (Held \& Soden 2006, Vecchi et al. 2006). An implication is that average large-scale overturning circulations, such as the Hadley and Walker cells, are apt to weaken (even as they change in character).

Other changes occur as the patterns of storm origins and tracks change; thus, the global atmospheric circulation plays a key role as well in the distribution of precipitation (Trenberth 1998, 1999a, Vecchi et al. 2006, IPCC 2007). The distribution and timing of floods and droughts is most profoundly affected by the cycle of ENSO events, particularly in the tropics and over much of the mid-latitudes of Pacific-rim countries. Even subtle changes in SSTs in the tropics can profoundly affect regional tropical precipitation. 
Energy and water constraints on tropical storms are reviewed by Trenberth \& Fasullo (2007), along with implications for global (Trenberth et al. 2007c) and Atlantic (Trenberth \& Fasullo 2008) tropical storms. The above arguments about changes in intensity and frequency of precipitation events also apply to tropical storms, although other factors (such as changes in wind shear) also come into play regionally.

\subsection{Factors in patterns of change}

Further clues to changes in precipitation come from local correlations of monthly mean precipitation with temperatures; see Fig. 6 (from Trenberth \& Shea 2005). At high latitudes, polewards of about $40^{\circ}$ in winter, correlations are generally positive. In these regions, $\mathrm{C}-\mathrm{C}$ relationships play a key role, as temperature controls how much moisture the atmosphere can hold, and the precipitation mainly occurs in polewards moving air in the warm sectors of extratropical cyclones (between the warm and cold fronts).

Over land throughout the tropics year round and over continents in summer, quite strong negative correlations rule (Fig. 6). In these regions, the availability of moisture appears to be a key, so that conditions tend to be either cool and wet or hot and dry. This relationship comes about from the following. In cyclonic regimes, more storminess brings cloudy skies and rain or snow, less solar radiation, and more soil moisture. The limited energy available goes more into evaporating moisture and evaporative cooling of the surface and less into sensible heating, resulting in lower temperatures. In contrast, anticyclonic regimes favor clear skies, more solar radiation, less rain and soil moisture, and thus latent energy fluxes are limited by the moisture supply, while sensible heat fluxes increase along with higher temperatures. Such conditions can only occur over land. An example is the changes that have taken place over North America (Qian et al. 2007). Related factors on land include a strong diurnal cycle and a predominance of convective rainfalls. Recycling of moisture is more important in summer than winter (Trenberth 1999b). However, given the right synoptic weather situation and time of day, severe convection and heavy rains can occur, with $\mathrm{C}-\mathrm{C}$ effects playing a role. Hence, on land, surface moisture effectively acts as an 'air conditioner', as heat used for evaporation acts to moisten the air rather than warm it. An observed consequence of this partitioning is that summers, in particular, generally tend to be either warm and dry or cool and wet (Trenberth \& Shea 2005).

Over the tropical Pacific Ocean positive correlations between temperatures and precipitation (Fig. 6) signal the important role of higher SSTs in controlling and favoring regions of convections and rains. On the other hand, negative correlations over tropical oceans signal places where teleconnections produce the downward branch of atmospheric circulation, clear skies, and, thus, SSTs become higher in the absence of rain and with increased solar radiation.

Beyond climate impacts on extremes, local and regional weather factors play an important role in the production of extreme weather events. The studies of the Buffalo Creek flood (Chen et al. 2001) provide evidence that burned regions in a river basin can be preferred regions for flash flooding. Mesoscale model simulations indicated preferred cloud and precipitation formation over the burned region due to enhanced sensible heat flux from the darker soil and to low water content in the soil after the fire. Runoff was also in-
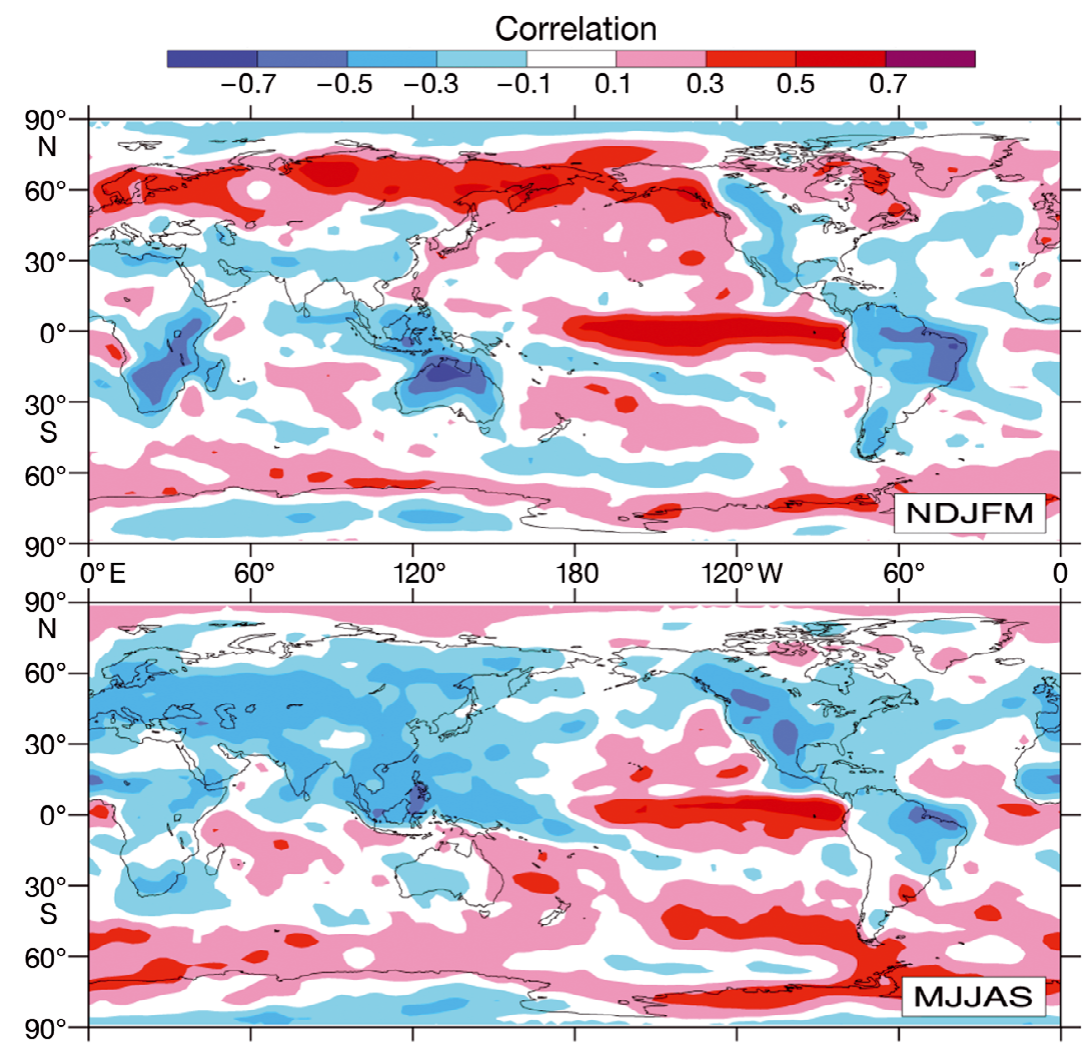

Fig. 6. Correlations between monthly mean anomalies of surface temperature and precipitation, grouped into the months of November to March (NDJFM) and May to September (MJJAS), for 1979-2002 (adapted from Trenberth \& Shea 2005) 
creased due to the more impervious soil and decreased vegetation. Moisture advection into the region was affected by farm irrigation within $100 \mathrm{~km}$ of the site. Thus, local and mesoscale features of river basins (especially characteristics of the soil and vegetation and its coupling to the boundary layer and clouds) may play an important role in extreme weather events, especially flood formation.

\subsection{Snow and snowpack}

As temperatures rise the likelihood of precipitation falling as rain rather than snow increases, especially in spring and autumn - at the beginning and end of the snow season-and in areas where temperatures are near freezing. Such changes have already been observed in many places, especially over land in the mid- and high latitudes of the Northern Hemisphere, leading to increased rains, but reduced areas of snowpack, and, consequently, leading to diminished water resources in summer, when they are most needed (e.g. Mote 2003, Knowles et al. 2006). In extratropical mountain areas, the winter snowpack forms a vital resource, not only for skiers, but also as a freshwater resource in the spring and summer as the snow melts. Warming leads to earlier snowmelt of the snow that exists, and greater evaporation and ablation. These factors all contribute to diminished snowpack. In the summer of 2002, in the western parts of the United States, exceptionally low snowpack and, subsequently, low soil moisture likely contributed substantially to the widespread intense drought because of the importance of recycling. On the other hand, mid-winter snows in continental regions may increase as temperatures rise, provided they are still below the freezing point.

\section{UNDERSTANDING MODEL PROJECTIONS}

Many insights have come from analysis of model results. A very robust finding in all climate models with global warming is for an increase in potential evapotranspiration. In the absence of precipitation, this leads to increased risk of drought, as surface drying is enhanced. It also leads to increased risk of heat waves and wildfires in association with such droughts; because once the soil moisture is depleted, all of the heating goes toward raising temperatures and wilting plants.

However, all models contain large errors in precipitation simulations, both in terms of mean fields and their annual cycle (such as the spurious migration of the ITCZ into the other hemisphere), as well as their characteristics: the intensity, frequency, and duration of precipitation, plus the amount (e.g. IPCC 2007, Bosilovich et al. 2008, Liepert \& Previdi 2009). It appears that many, perhaps all, global climate and numerical weather prediction models and even many high-resolution regional models have a premature onset of convection and overly frequent precipitation with insufficient intensity (Yang \& Slingo 2001, Dai \& Trenberth 2004). The latter weaknesses are most readily manifested as errors in the diurnal cycle. Results may be more robust in the extratropics (Lorenz \& DeWeaver 2007).

Changes in the intensity of precipitation have been explored in climate models and confirm the expectations outlined here, e.g. the ECHAM4/OPYC3 model (Semenov \& Bengtsson 2002) and the Hadley Centre model (Allen \& Ingram 2002), which show at the time of doubling of carbon dioxide in the model simulations that rainfall intensities less than about the 85th percentile decrease in frequency, while heavy events increase at close to the $\mathrm{C}-\mathrm{C}$ rate. Models may, in fact, underestimate amplification in extremes (Allan \& Soden 2008). Climate models typically predict an increase in the global amount of precipitation of $1-2 \%$ per $1^{\circ} \mathrm{C}$ warming of the global mean surface temperature (Allen \& Ingram 2002).

Tebaldi et al. (2006) and IPCC (2007) show that precipitation intensity increases in IPCC climate models throughout the 21st century. This has been explored very thoroughly by Sun et al. (2007), who examined the response of climate models used in the AR4 IPCC assessment for 2080-2099 versus 1980-1999 for various scenarios, with results normalized by the global mean surface temperature. They found that global TCWV increased at a rate of $9 \%$ $\mathrm{K}^{-1}$, while precipitation increased at $1.7 \% \mathrm{~K}^{-1}$. Precipitation frequency decreased at $-0.8 \% \mathrm{~K}^{-1}$, and precipitation intensity increased at $2 \% \mathrm{~K}^{-1}$. The increase in TCWV is consistent with the C-C relationship for changes in saturation specific humidity $q_{\mathrm{s}}$ with temperature changes somewhat above the Earth's surface, where they are larger than at the surface; in the tropics, the saturation adiabatic lapse rate is largely responsible for this relationship. They also found that there was a much higher frequency of more intense precipitation events contributing to the total amount of precipitation, especially the frequency of events of $>50 \mathrm{~mm} \mathrm{~d}^{-1}$. Their findings are consistent with the expectations that, with increases in TCWV with rising temperatures, moisture convergence in storms should be increased, and the resulting increase in latent heating can invigorate the storm and further increase moisture convergence. However, important feedbacks occur through changes in stability and changes in winds. 
O'Gorman \& Schneider (2009) also examined these aspects for the AR4 models and found that precipitation at the 99.9th percentile increased at about $6 \% \mathrm{~K}^{-1}$ for 2081-2100 relative to 1981-2000. There was considerable model scatter at the extremes, but the changes were fairly robust. They noted that condensa- tion is proportional to the product of vertical motion and the vertical gradient of $q_{\mathrm{s}}$. The latter does not increase as rapidly as $q_{\mathrm{s}}$ itself. For example, at temperatures of $280 \mathrm{~K}$ and pressures of $850 \mathrm{hPa}$, the vertical gradient of $q_{\mathrm{s}}$ increases at $2.9 \% \mathrm{~K}^{-1}$ versus $6.9 \% \mathrm{~K}^{-1}$ for $q_{\mathrm{s}}$. Thus, they confirmed that changes were linked to
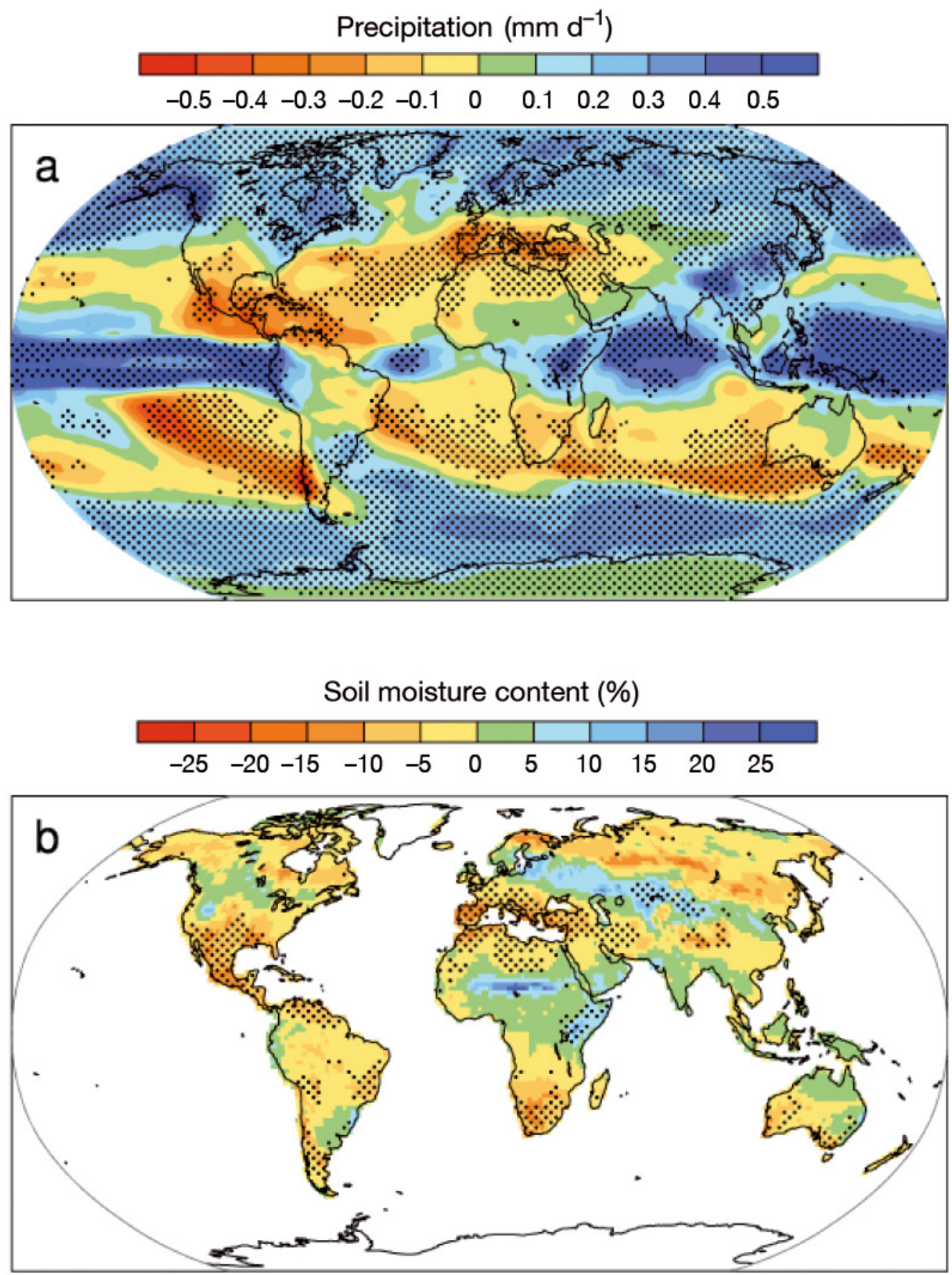

Fig. 7. Multi-model mean changes in (a) precipitation and (b) soil moisture content. To indicate consistency in the sign of change, regions are stippled where at least $80 \%$ of models agree on the sign of the mean change. Changes are annual means for the SRES A1B scenario (Special Reports on Emissions Scenarios, IPCC) for the period 2080-2099 relative to 1980-1999. Soil moisture changes are shown at land points with valid data from at least 10 models. Taken from IPCC (2007, their Fig. 10.12) 
increased convergence of higher water vapor amounts, modified by changes in static stability and atmospheric circulation to give the values of about $6 \% \mathrm{~K}^{-1}$. Differences among models were especially dependent on vertical motion changes.

In the Northern Hemisphere for the 21st century, a robust pattern of increased precipitation polewards of about $45^{\circ} \mathrm{N}$ is projected by the IPCC (2007), due to the increase in water vapor in the atmosphere and the resulting increase in vapor transport from lower latitudes (Fig. 7). This is accompanied by decreased subtropical precipitation, although less so over Asia. Extratropical storm tracks are projected to move poleward (Yin 2005), with consequent changes in wind, precipitation, and temperature patterns, continuing the broad pattern of observed trends over the last halfcentury. Along with a poleward expansion of subtropical high-pressure systems, this leads to a drying tendency in the subtropics that is especially pronounced at the higher-latitude margins of the subtropics. The predominant pattern here is one that exemplifies the 'rich get richer and the poor get poorer' syndrome. At the same time that the intensity increases, the number of dry days also increases and soil moisture decreases in many places, including many areas where precipitation increases (Tebaldi et al. 2006, IPCC 2007). These tendencies arise from the reduction in frequency of precipitation, the increases in intensity and runoff, and the increases in evapotranspiration.

Further studies of the AR4 models to see how the disparity between the approximately $7 \% \mathrm{~K}^{-1}$ increase in TCWV and the $2 \% \mathrm{~K}^{-1}$ increase in precipitation arises have been pursued by Stephens \& Ellis (2008) and Richter \& Xie (2008). The latter were able to linearize the contributions to change in surface moisture fluxes and found that over $90 \mathrm{yr}$ in the 21st century the surface wind speed dropped by a very small amount (0.02 $\left.\mathrm{m} \mathrm{s}^{-1}\right)$, air-sea temperature differences decreased by about $0.2 \mathrm{~K}$, and surface relative humidity increased by $1 \%$ over the oceans, all of which account for the drop in surface evaporation to $2 \% \mathrm{~K}^{-1}$ relative to the constant relative humidity assumption and C-C effects. Stephens \& Ellis (2008) point out that a dominant influence on the surface heat budget that controls the energy available for evaporation is the downwelling long-wave radiation associated with increasing GHGs.

The IPCC (2007) also concludes that future tropical cyclones (typhoons and hurricanes) will likely become more intense, with larger peak wind speeds and more heavy precipitation associated with ongoing increases of tropical SSTs. Partly because an intense tropical cyclone takes heat out of the ocean and mixes the ocean, leaving behind a much stronger cold wake than a more modest storm, there may be fewer tropical cyclones on the whole. Possible increases in static stability also lead to fewer tropical cyclones. Nonetheless, an increased risk of flooding is a likely outcome from land-falling tropical storms (Trenberth et al. 2007c). Recent results with higher resolution climate models and downscaling methods suggest an increase in the strong Category 4 and 5 storms in the Atlantic, even as the total number of storms decreases (Bender et al. 2010).

\section{FUTURE CHALLENGES}

As can be seen from the above, finding out what is happening to precipitation and storms is vital. Fortunately, recent and continuing advancement of remote sensing (such as those on the Tropical Rainfall Measurement Mission and a proposed constellation of similar satellites) and innovative global precipitation retrieval techniques are improving in accuracy at relatively high spatial and temporal scales. Global global gridded values and maps of precipitation every 3-6 h are now available, and hourly precipitation analyses should be available in the near future. These efforts provide a potential data source that can be used to investigate variability - in terms of intensity and frequency - in heavy precipitation across various climate regions.

The most robust changes in precipitation with climate change are those associated with the thermodynamic aspects that relate to the C-C relationship. More challenging are the dynamical changes that tend to depend more on uncertain model results. Special issues include:

Intermittency: Most of the time it does not precipitate and seldom all day: most analyses are of daily means, but hourly values are needed both in observations and models.

Land versus ocean: There are huge differences in water availability and important differences in how precipitation relates to temperature and is projected to change.

Normalization: The C-C relationship suggests that rather than absolute values or a threshold exceedance, changes depend on the climatology and are better analyzed as a percent change. The percent per change in global mean surface temperature has been one metric, but perhaps temperatures at other levels, zonal means, or local values should be used.

Differences among datasets occur in all water-related variables. The data are inherently messy, owing to the intermittency of precipitation and small spatial scales, and there is therefore a need for high-frequency sampling. Spatial scales vary from tornadoes to continental-scale droughts. Substantial differences remain among ground-based and remote-sensing observa- 
tions. Often data are not available with the right sampling. Extremes are inherently rare and, therefore, require a lot of data to obtain reliable results.

Definitions: There can be substantial issues over model definitions being different to observational ones, and model grid box values may not be comparable to the mean of grid box values from observations, let alone station values. There can also be issues with terminology, and confusion over high-impact (but not really extreme) events. It must be recognized that there are several kinds of droughts (meteorologicalrelated to absence of precipitation, agricultural-related to soil moisture deficits, and hydrological-related to lake level and stream flow reductions).

Modeling: Confidence in model results for changes in extremes is tempered by the large scatter among the extremes in modeling today's climate, especially in the tropics and subtropics (Kharin et al. 2007), which relates to poor depiction of transient tropical disturbances, including easterly waves, Madden-Julian Oscillations, tropical storms, and hurricanes (Lin et al. 2006). These phenomena are very resolution dependent, but also depend on parameterizations of sub-grid-scale convection, the shortcomings of which are revealed in diurnal cycle simulations; models produce precipitation that is too frequent and with insufficient intensity (Yang \& Slingo 2001, Trenberth et al. 2003, Dai \& Trenberth 2004, Dai 2006b). Major challenges remain to improve model simulations of the hydrological cycle.

Nonetheless, it is evident from the above that climate change has large direct impacts on several aspects of the hydrological cycle-in particular, increases in extremes-making managing and using water resources more challenging. Dealing with drought one year and floods the next (as in Europe in 2002 and 2003) presents major challenges for water managers concerned with how to save in times of excess for those times when there is too little.

Acknowledgements. Jessica Mackaro helped with the figures. The National Center for Atmospheric Research is sponsored by the National Science Foundation. This research was partially sponsored by the NOAA CCDD program under Grant NA07OAR4310051 and NASA under Grant NNX09AH89G.

\section{LITERATURE CITED}

Adam JC, Lettenmaier DP (2003) Adjustment of global gridded precipitation for systematic bias. J Geophys Res 108: 4257. doi:10.1029/2002JD002499

Adam JC, Clark EA, Lettenmaier DP, Wood EF (2006) Correction of global precipitation products for orographic effects. J Clim 19:15-38

- Alexander LV, Zhang X, Peterson TC, Caesar J, and others (2006) Global observed changes in daily climate extremes of temperature and precipitation. J Geophys Res 111: D05109. doi:10.1029/2005JD006290
Allen MR, Ingram WJ (2002) Constraints on future changes in climate and the hydrologic cycle. Nature 419:224-232

Allan RP, Soden BJ (2008) Atmospheric warming and the amplification of precipitation extremes. Science 321: 1481-1494

Alpert P, Ben-Gai T, Baharad A, Benjamini Y and others (2002) The paradoxical increase of Mediterranean extreme daily rainfall in spite of decrease in total values. Geophys Res Lett 29. doi:10.1029/2001GL013554

Bender MA, Knutson TR, Tuleya RE, Sirutis JJ, Vecchi GA, Garner ST, Held IM (2010) Modeled impact of anthropogenic warming on the frequency of intense Atlantic hurricanes. Science 327:454-458

> Bosilovich MG, Chen J, Robertson FR, Adler RF (2008) Evaluation of global precipitation in reanalyses. J Appl Meteorol Climatol 47:2279-2299

Chen F, Warner T, Manning K (2001) Sensitivity of orographic moist convection to landscape variability: a study of the Buffalo Creek, Colorado, flash flood case of 1996. J Atmos Sci 58:3204-3223

Chou C, Neelin JD (2004) Mechanisms of global warming impacts on regional tropical precipitation. J Clim 17: $2688-2701$

Chou C, Neelin JD, Chen CA, Tu JY (2009) Evaluating the 'rich-get-richer' mechanism in tropical precipitation change under global warming. J Clim 22:1982-2005

Dai A (2001) Global precipitation and thunderstorm frequencies. I. Seasonal and interannual variations. J Clim 14:1092-1111

Dai A (2006a) Recent climatology, variability and trends in global surface humidity. J Clim 19:3589-3606

> Dai A (2006b) Precipitation characteristics in eighteen coupled climate models. J Clim 19:4605-4630

Dai A, Trenberth KE (2004) The diurnal cycle and its depiction in the Community Climate System Model. J Clim 17:930-951

- Dai A, Trenberth KE, Qian T (2004) A global dataset of Palmer drought severity index for 1870-2002: relationship with soil moisture and effects of surface warming. J Hydrometeorol 5:1117-1130

> Dai A, Qian T, Trenberth KE, Milliman JD (2009) Changes in continental freshwater discharge from 1949-2004. J Clim 22:2773-2791

Diaz HF, Markgraf V (eds) (2000) El Niño and the southern oscillation, multiscale variability and global and regional impacts. Cambridge University Press, Cambridge

> Durre I, Williams CN, Yin X, Vose RS (2009) Radiosondebased trends in precipitable water over the Northern Hemisphere: an update. J Geophys Res 114:D05112. doi: 10.1029/2008JD010989

Easterling DR, Evans JL, Groisman PYa, Karl TR, Kunkel KE, Ambenje P (2000) Observed variability and trends in extreme climate events: a brief review. Bull Am Meteorol Soc 81:417-425

> Gedney N, Cox PM, Betts RA, Boucher O and others (2006) Detection of a direct carbon dioxide effect in continental river runoff records. Nature 439:835-838

Giannini A, Saravannan R, Chang P (2003) Ocean forcing of Sahel rainfall on interannual to interdecadal time scales. Science 302:1027-1030

> Groisman PYa, Knight RW (2008) Prolonged dry episodes over the conterminous United States: new tendencies emerging during the last 40 years. J Clim 21:1850-1862

> Groisman PYa, Knight RW, Karl TR, Easterling DR and others (2004) Contemporary changes of the hydrological cycle over the contiguous United States: trends derived from in situ observations. J Hydrometeorol 5:64-85 
Groisman PYa, Knight RW, Easterling DR, Karl TR and others (2005) Trends in intense precipitation in the climate record. J Clim 18:1326-1350

> Gu G, Adler RF, Huffman GJ, Curtis S (2007) Tropical rainfall variability on interannual-to-interdecadal/longer-time scales derived from the GPCP monthly product. J Clim 20: 4033-4046

Held IM, Soden BJ (2006) Robust responses of the hydrological cycle to global warming. J Clim 19:5686-5699

Hoerling MP, Hurrell JW, Eischeid J, Phillips AS (2006) Detection and attribution of 20th Century northern and southern African monsoon change. J Clim 19:3989-4008

Huffman GJ, Adler RF, Bolvin DT, Gu G (2009) Improving the global precipitation record: GPCP Version 2.1. Geophys Res Lett 36:L17808. doi:10.1029/2009GL040000

> Huntington TG (2006) Evidence for intensification of the global water cycle: review and synthesis. J Hydrol (Amst) 319:83-95

Hurrell JW, Kushnir Y, Ottersen G, Visbeck M (eds) (2003) The North Atlantic Oscillation: climate significance and environmental impacts. Geophysical Monograph No. 134, American Geophysics Union, Washington, DC

IPCC (Intergovernmental Panel on Climate Change) (2007) Climate change 2007. The physical science basis. In: Solomon Q, Qin D, Manning M, Chen Z and others (eds) Contribution of Working Group 1 to the 4 th assessment report of the Intergovernmental Panel on Climate Change. Cambridge University Press, Cambridge

Karl TR, Trenberth KE (2003) Modern global climate change. Science 302:1719-1723

Kharin VV, Zwiers FW, Zhang X, Hegerl GC (2007) Changes in temperature and precipitation extremes in the IPCC ensemble of global coupled model simulations. J Clim 20: 1419-1444

Klein Tank AMG, Können GP (2003) Trends in indices of daily temperature and precipitation extremes in Europe, 1946-1999. J Clim 16:3665-3680

Klein Tank AMG, Peterson TC, Quadir DA, Dorji S and others (2006) Changes in daily temperature and precipitation extremes in central and south Asia. J Geophys Res 111:D16105. doi:10.1029/2005JD006316

Knowles N, Dettinger M, Cayan D (2006) Trends in snowfall versus rainfall for the eastern United States. J Clim 19: 4545-4559

Krajewski WF, Villarini G, Smith JA (2010) Radar-rainfall uncertainties. Bull Am Meteorol Soc 91:87-94

Liepert BG, Previdi M (2009) Do models and observations disagree on the rainfall response to global warming? J Clim 22:3156-3166

Lin JL, Kiladis GN, Mapes BE, Weickmann KM and others (2006) Tropical intraseasonal variability in 14 IPCC AR4 climate models. I. Convective signals. J Clim 19:2665-2690

Liu SC, Fu C, Shiu CJ, Chen JP, Wu F (2009) Temperature dependence of global precipitation extremes. Geophys Res Lett 36:L17702. doi:10.1029/2009GL040218

Lorenz DJ, DeWeaver ET (2007) The response of the extratopical hydrological cycle to global warming. J Clim 20: 3470-3484

Milly PCD, Wetherald RT, Dunne KA, Delworth TL (2002) Increasing risk of great floods in a changing climate. Nature 415:514-517

- Mote PW (2003) Trends in snow water equivalent in the Pacific Northwest and their climatic causes. Geophys Res Lett 30:1601. doi:10.1029/2003GL017258

> Murnane RJ (2004) Climate research and reinsurance. Bull Am Meteorol Soc 85:697-707

Neelin JD, Munnich M, Su H, Meyerson JE, Holloway CE
(2006) Tropical drying trends in global warming models and observations. Proc Natl Acad Sci USA 103:6110-6115. doi:10.1073/pnas.0601798103

O'Gorman PA, Schneider T (2009) The physical basis for increases in precipitation extremes in simulations of 21stcentury climate change. Proc Natl Acad Sci USA 106: 14773-14777

Peterson TC, Taylor MA, Demeritte R, Duncombe DL and others (2002) Recent changes in climate extremes in the Caribbean region. J Geophys Res 107:4601. doi:10.1029/ 2002JD002251

- Qian T, Dai A, Trenberth KE (2007) Hydroclimatic trends in the Mississippi River basin from 1948 to 2004. J Clim 20: 4599-4614

> Richter I, Xie SP (2008) Muted precipitation increase in global warming simulations: a surface evaporation perspective. J Geophys Res 113:D24118. doi:10.1029/2008JD010561

> Santer BD, Mears C, Wentz FJ, Taylor KE and others (2007) Identification of human-induced changes in atmospheric moisture content. Proc Natl Acad Sci USA 104:15248-15253

Schlosser CA, Houser PR (2007) Assessing a satellite-era perspective of the global water cycle. J Clim 20:1316-1338

Semenov VA, Bengtsson L (2002) Secular trends in daily precipitation characteristics: greenhouse gas simulation with a coupled AOGCM. Clim Dyn 19:123-140

Smith TM, Reynolds RW, Peterson TC, Lawrimore J (2008) Improvements to NOAA's historical merged land-ocean surface temperature analysis (1880-2006). J Clim 21: $2283-2296$

> Soden BJ, Jackson DL, Ramaswamy V, Schwarzkopf D, Xianglei Huang (2005) The radiative signature of upper tropospheric moistening. Science 310:841-844

Stephens GL, Ellis TD (2008) Controls of global-mean precipitation increases in global warming GCM experiments. J Clim 21:6141-6155

Stevens B, Feingold G (2009) Untangling aerosol effects on clouds and precipitation in a buffered system. Nature 461: $607-613$

Sun Y, Solomon S, Dai A, Portmann R (2007) How often will it rain? J Clim 20:4801-4818

> Tebaldi C, Hayhoe K, Arblaster JM, Meehl GA (2006) Going to the extremes: an intercomparison of model-simulated historical and future changes in extreme events. Clim Change 79:185-211

Trenberth KE (1998) Atmospheric moisture residence times and cycling: implications for rainfall rates and climate change. Clim Change 39:667-694

> Trenberth KE (1999a) Conceptual framework for changes of extremes of the hydrological cycle with climate change. Clim Change 42:327-339

Trenberth KE (1999b) Atmospheric moisture recycling: role of advection and local evaporation. J Clim 12:1368-1381

Trenberth KE, Caron JM (2000) The Southern Oscillation revisited: sea level pressures, surface temperatures and precipitation. J Clim 13:4358-4365

Trenberth KE, Dai A (2007) Effects of Mount Pinatubo volcanic eruption on the hydrological cycle as an analog of geoengineering. Geophys Res Lett 34:L15702. doi: 10.1029/2007GL030524

Trenberth KE, Fasullo J (2007) Water and energy budgets of hurricanes and implications for climate change. J Geophys Res 112:D23107. doi:10.1029/2006JD008304

Trenberth KE, Fasullo J (2008) Energy budgets of Atlantic hurricanes and changes from 1970. Geochem Geophys Geosyst 9:Q09V08. doi:10.1029/2007GC001847

$>$ Trenberth KE, Fasullo JT (2009) Global warming due to increasing absorbed solar radiation. Geophys Res Lett 
36:L07706. doi:10.1029/2009GL037527

Trenberth KE, Guillemot CJ (1996) Physical processes involved in the 1988 drought and 1993 floods in North America. J Clim 9:1288-1298

Trenberth KE, Shea DJ (2005) Relationships between precipitation and surface temperature. Geophys Res Lett 32: L14703. doi:10.1029/2005GL022760

Trenberth KE, Dai A, Rasmussen RM, Parsons DB (2003) The changing character of precipitation. Bull Am Meteorol Soc 84:1205-1217

Trenberth KE, Fasullo J, Smith L (2005) Trends and variability in column-integrated water vapor. Clim Dyn 24:741-758

Trenberth KE, Jones PD, Ambenje P, Bojariu R and others (2007a) Observations: surface and atmospheric climate change. In: Solomon S, Qin D, Manning M, Chen Z and others (eds) Climate change 2007. The physical science basis. Intergovernmental Panel on Climate Change 4th assessment report. Cambridge University Press, Cambridge, $\mathrm{p} 235-336$

Trenberth KE, Smith L, Qian T, Dai A, Fasullo J (2007b) Estimates of the global water budget and its annual cycle using observational and model data. J Hydrometeorol 8:758-769

Submitted: March 8, 2010; Accepted: October 18, 2010
Trenberth KE, Davis CA, Fasullo J (2007c) Water and energy budgets of hurricanes: case studies of Ivan and Katrina. J Geophys Res 112:D23106. doi:10.1029/2006JD008303

> Trenberth KE, Fasullo J, Kiehl J (2009) Earth's global energy budget. Bull Am Meteorol Soc 90:311-323

Vecchi GA, Soden BJ, Wittenberg AT, Held IM and others (2006) Weakening of tropical Pacific atmospheric circulation due to anthropogenic forcing. Nature 441:73-76

Wentz FJ, Ricciardulli L, Hilburn K, Mears C (2007) How much more rain will global warming bring? Science 317: 233-235

Willett KM, Jones PD, Gillett NP, Thorne P (2008) Recent changes in surface humidity: development of the HadCRUH dataset. J Clim 21:5364-5383

Yang GY, Slingo J (2001) The diurnal cycle in the Tropics. Mon Weather Rev 129:784-801

Yin JH (2005) A consistent poleward shift of the storm tracks in simulations of 21st century climate. Geophys Res Lett 32:L18701. doi:10.1029/2005GL023684

Yu LS, Weller RA (2007) Objectively analyzed air-sea heat fluxes for the global ice-free oceans (1981-2005). Bull Am Meteorol Soc 88:527-539

Proofs received from author(s): February 7, 2011 